\title{
QUANTITATIVE RELATIONSHIP BETWEEN BASAL METABOLIC RATE AND THYROID DOSAGE IN PATIENTS WITH TRUE MYXEDEMA
}

\author{
By A. W. WINKLER, J. CRISCUOLO,1 AND P. H. LAVIETES \\ (From the Department of Internal Medicine, Yale University School of Medicine, and the \\ Medical Service of the New Haven Hospital, New Haven)
}

(Received for publication December 9, 1942)

Patients with myxedema differ from other subjects in their response to oral thyroid extract (1). The precise nature of this difference has not, however, been clearly defined. The present study originated in the observation that certain nonmyxedematous subjects could tolerate very large daily doses of oral thyroid extract without demonstrable effect on the basal metabolic rate. This behavior, so different from the acute sensitivity of patients with true myxedema even to small amounts of thyroid extract, demanded further investigation. As a preliminary step, the present paper supplements the work of Means and Lerman (2) in defining as exactly as possible the relationship between thyroid dosage and metabolic response in patients with true myxedema.

\section{MATERIAL AND METHODS}

Clinical diagnostic criteria. Twenty-eight patients with fully developed myxedema were included. The difficulties in some cases of making a positive diagnosis were fully recognized, and all questionable cases were rejected. In fifteen cases, the clinical diagnosis was confirmed by the demonstration of a high serum cholesterol, by a low blood or serum iodine, or by both. ${ }^{2}$ The remaining patients had been seen before the introduction of these techniques of blood chemistry, or refused to discontinue thyroid medication, so that the diagnosis rested on clinical grounds. These included, in every case, the initial presence of the facies and other stigmata of the disease and the prompt and complete return of the patient to a normal state with daily administration of one or two grains of thyroid extract. In no case was an initially low basal metabolic rate alone considered evidence of myxedema. Subjective improvement on thyroid medication without striking objective evidence of physical change was also excluded

1 Some of the data upon which this paper is based were included in a thesis submitted by Joseph Criscuolo to the Yale University School of Medicine, in partial fulfillment of the requirements for the degree of Doctor of Medicine, 1938.

${ }^{2} \mathrm{We}$ are indebted to Dr. Evelyn Man and to Dr. Douglas Riggs for these chemical data. from consideration. In several instances, the diagnosis was proven by witholding thyroid until definite evidence of myxedema manifested itself. The time necessary for this to develop varied considerably from patient to patient, but was not less than two weeks nor more than eight weeks. Two cases with total thyroidectomy for heart disease were included. Subjects with hypometabolism following subtotal thyroidectomy were not in general included, since the thyroid deficiency in these patients is apt to be transitory or at least incomplete $(3,4)$. The only exception was a single subject, followed for many years, who developed full-blown myxedema whenever thyroid extract was discontinued.

Technique of study. The basal metabolic rate (which will hereafter be referred to as the "BMR") of each patient was determined from time to time over a period of months or years. The BMR was then correlated with the dose of dried thyroid which the patient had been receiving during the preceding month. Tablets of U. S. P. dried thyroid were used. The patients were usually ambulatory, although a few observations on hospitalized patients are included. The BMR was determined with a Benedict-Roth machine in the usual fashion, in the morning, after thirty to sixty minutes of complete physical rest. Patients were all in the postabsorptive state. Two curves were taken, and if they did not check within five per cent, a third curve was obtained. BMR determinations in the same patient done on successive days usually checked within less than ten per cent.

Mode of analysis. BMR determinations were included only if the patient had been on the same daily dose of thyroid for at least one month before the metabolism test. The patient was regularly questioned at the time of the test, and the determination was excluded if there had been any irregularity of dosage. No subjects known to be habitually careless about taking medication were included. All acceptable values of the BMR in the same subject corresponding to each level of dosage were then collected, and an average taken. These averages are included in Table I; the small figures beside each average indicate the number of individual BMR determinations upon which the average was based. The average deviation of the mean is also included in all instances in which five or more determinations were available. An exception to this procedure was made in the selection of the BMR associated with no administration of thyroid. Here, the lowest rather than the average value was taken, since at most, only two or three determinations at this level 
TABLE I

Basal metabolic rate and daily thyroid dosage

\begin{tabular}{|c|c|c|c|c|c|c|c|c|c|c|c|c|c|}
\hline \multirow{2}{*}{ Case } & \multicolumn{13}{|c|}{$\begin{array}{l}\text { Average BMR while taking oral thyroid daily* } \\
\text { Dosage, grains per day }\end{array}$} \\
\hline & ot & 0.25 & 0.50 & 0.75 & 1.00 & 1.25 & 1.50 & 1.75 & 2.00 & 2.25 & 2.50 & 2.75 & 3.00 \\
\hline $\begin{array}{r}1 \\
2 \\
3 \\
4 \\
5 \\
6 \\
7 \\
8 \\
9 \\
10 \\
11 \\
12 \\
13 \ddagger \\
14 \\
15 \\
16 \\
17 \\
18 \\
19 \\
20 \\
21 \\
22 \\
23 \\
24 \\
25 \\
26 \\
27 \\
28\end{array}$ & $\begin{array}{l}-35 \\
-41 \\
-34 \\
-30 \\
-38 \\
-38 \\
-42 \\
-31 \\
-30 \\
-34 \\
-31 \\
(-22) 8 \\
(-18) 8 \\
(-26) 8 \\
-31 \\
-43 \\
-39 \\
-27 \\
-24 \\
\\
-38 \\
-41 \\
-34 \\
-48 \\
-19 \\
-28\end{array}$ & $\begin{array}{l}-11_{4} \\
-24_{1}\end{array}$ & $\begin{array}{l}-23_{3} \\
-33_{1} \\
-16_{2}\end{array}$ & $\begin{array}{l}-24_{1} \\
-27_{1}\end{array}$ & $\begin{array}{l}-21_{5} \pm 11 \\
-44_{1} \\
-10_{1} \\
-44_{3} \\
-25_{1} \\
-11_{1} \\
-3_{7} \pm 3 \\
-16_{2} \\
+5_{1} \\
+7_{9} \pm 5 \\
-6_{3}\end{array}$ & & $\begin{array}{l}+1_{1} \\
-5_{9} \pm 2 \\
-16_{20} \pm 6 \\
-12_{1} \\
\\
+11_{4} \\
\\
-26_{1} \\
-11_{1} \\
-14_{1}\end{array}$ & & $\begin{array}{c}-10_{8} \pm 5 \\
+4_{6} \pm 6 \\
+4_{1} \\
-11_{9} \pm 3 \\
-4_{2} \\
-4_{10} \pm 7 \\
-15_{1} \\
+14_{1} \\
-3_{2} \\
+8_{1} \\
-5_{2} \\
\\
\\
-13_{1} \\
-20_{2} \\
-9_{3} \\
-4_{3} \\
-9_{1} \\
-3_{2} \\
\\
-11_{1} \\
-11_{1} \\
-4_{9} \pm 4\end{array}$ & $-5_{7} \pm 4$ & $\begin{array}{l}-5, \\
+1,\end{array}$ & & $\begin{array}{l}-9_{7} \pm 5 \\
-3_{1} \\
-11_{16} \pm 5 \\
-9_{2} \\
+13_{1}\end{array}$ \\
\hline
\end{tabular}

* Large figures represent average BMR's; small figures represent number of individual BMR determinations. t Minimum BMR.

$¥ B M R$ on 0.125 grains of thyroid daily was -15 per cent.

\& Lowest BMR following total thyroidectomy; true myxedema not allowed to develop.

were available, and since it was felt that a minimum figure would be less misleading than an average one.

\section{GENERAL RESULTS}

The averages of Table I, calculated in the manner which has just been described, indicate at once two general facts. (1) The dose necessary to restore the BMR to normal varied from one to three grains of thyroid daily. In a few patients, one grain daily sufficed; the majority required about one and one-half or two grains, while some at times required as much as three grains daily. In no subject, with the possible exception of case 23 , was there any indication that more than three grains daily were necessary. Patients requiring only one or one and a half grains daily usually became nervous and ill if given more (case 10, for example). The requirements for thyroid were apt to be somewhat greater in heavy than in slight subjects, but this correlation was very irregular.
There is no evidence of any failure of response to thyroid. In every instance, the BMR during thyroid medication remained consistently greater than the BMR while no medication was being given.

\section{QUANTITATIVE RELATIONSHIPS}

In all cases, there was a positive correlation between the height of the BMR and the current dose of thyroid. On a statistical basis, this is apparent in Figure 1, in which all values of Table $I$ are represented by points. The distribution of points is similar to that observed by Means and Lerman in their study of myxedema (2). The plot of Figure 1 is, however, misleading, in that it suggests that the first increments of thyroid substance are much more effective in raising the BMR than are subsequent increments. This conclusion is not warranted, since all patients were not tried out on all levels of dosage. As a rule, each patient was 
given just enough thyroid to bring the BMR back to normal. This might vary from one to three grains daily, and might vary from time to time in the same patient. Patients requiring only one grain daily to restore their BMR to normal were never given two or three grains daily, while, on the other hand, only those patients requiring the full three grains daily to restore the BMR to normal are included in the three grain column. Had all patients been given three grains daily, it seems

\section{BMR}

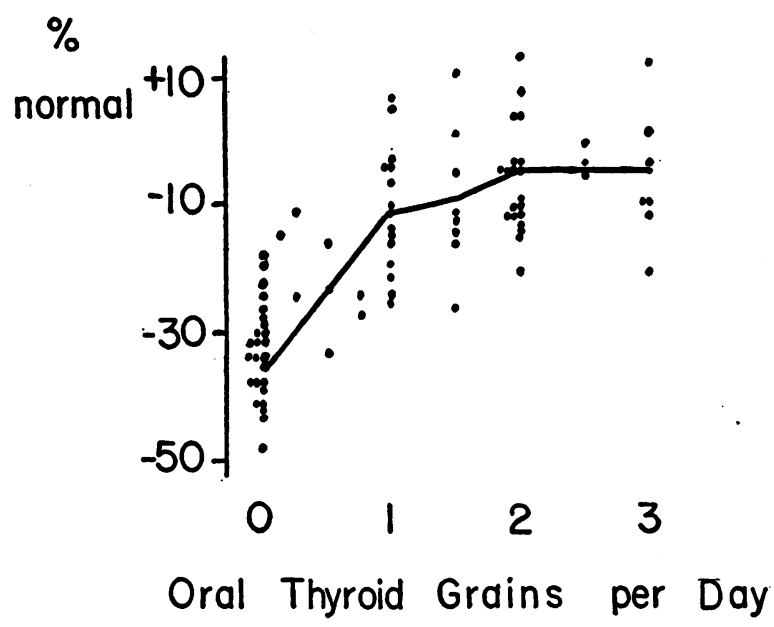

Fig. 1. Statistical Relationship Between BMR and Dosage of Oral Thyroid in the Twenty-Eight Cases of TABLE I

The heavy line connects the average values for the BMR at each level of thyroid dosage.

most probable, on the basis of acute experiments, that a number of supranormal values would have been found in the three grain column, with a corresponding increase in the average BMR. The apparent evidence for "diminishing return" from thyroid medication has, therefore, little validity, since it may only represent the artificial conditions under which these averages were obtained.

In principle, a more satisfactory approach to this matter might be made by following the BMR in the same individual at different levels of dosage. There is evidently a distinct linearity in many cases, such as $1,2,8,9,10$, and 11 , while in several others, such as $3,4,5$, and 6 , the curve unmistakably flattens out as higher levels are reached. If we confine our attention to the effects of daily dosages of one and of two grains, respectively, in the same individual, the variability is equally evident. Of the eight subjects so studied, four showed as much increment of BMR from the second grain as from the first, while four showed a smaller increment from the second grain.

Here too, however, the manner in which the thyroid was administered must be considered before the results can be interpreted. In all cases with flattening of the curve at higher levels of dosage, the patients were not tested impartially at various levels of dosage. Instead, the dose was usually increased or decreased in order to keep the level of the BMR constant. For example, in cases 4 and 6 , followed for many years, it was customary to raise the dose to three grains daily whenever the BMR fell a little or the patient gained a little weight, and to reduce it again to two grains daily whenever the BMR rose a bit or the patient became nervous. Indeed, in case 6 , the policy of raising the dose to three grains whenever the BMR tended spontaneously to be lower resulted in a lower average BMR while on three than while on two grains daily! The general result was, of course, to keep the BMR about the same regardless of dose. Attempts were made in several instances deliberately to raise the thyroid dosage above the amount required to restore the BMR to normal, but usually the patients refused to continue the increased dosage for any length of time, because of nervousness, tachycardia, or weight loss. In case 1 , for example, thyroid dosage was experimentally varied between one and two grains daily, regardless of the previous BMR or the patient's condition. Omitting the elevated value on one and a half grains daily, which was based on one BMR determination only, the line between the levels at zero, one, and two grains is entirely straight.

\section{VARIABILITY OF THE BMR IN THE SAME SUBJECT}

It has already been pointed out that the same patient may require more or less thyroid at different times in order to maintain the same level of the BMR. This means that the BMR in the myxedematous, and supposedly thyroidless, individual may vary spontaneously from time to time. $\mathrm{Pa}$ tients differ with respect to the degree of variability of the BMR. Thus, in case 23 , the BMR on three grains daily varied between -9 per cent and -29 per cent, and in case 3 , the BMR on one and 
a half grains daily was at one time as low as -28 per cent and at another as high as +2 per cent. This is a wide range of variability; in most subjects, the fluctuations were somewhat less extreme. Often, however, the variation exceeded that to be expected from the technical uncertainties of $B M R$ determination.

\section{ABSENCE OF TOLERANCE TO THYROID EXTRACT}

The variations which have just been described seemed to be cyclical rather than progressive, and in the same patient, the BMR on a given dose might fluctuate over a period of years without any long term trend. No tendency toward "tolerance" to larger and larger doses of dried thyroid, such as has occasionally been observed in non-myxedematous subjects, could be detected. This is clearly brought out in Table II. The dose of thyroid

TABLE II

Absence of tolerance to oral thyroid in patients with myxedema, followed for a number of years

\begin{tabular}{|c|c|c|c|}
\hline \multirow{2}{*}{ Case } & \multirow{2}{*}{$\begin{array}{c}\text { Years } \\
\text { followed }\end{array}$} & \multicolumn{2}{|c|}{$\begin{array}{l}\text { Daily dose of thyroid } \\
\text { necessary to maintain normal BMR }\end{array}$} \\
\hline & & $\begin{array}{l}\text { When first } \\
\text { seen }\end{array}$ & $\begin{array}{l}\text { When last } \\
\text { seen }\end{array}$ \\
\hline $\begin{array}{l}1 \\
2 \\
3 \\
4 \\
5 \\
6 \\
7 \\
8\end{array}$ & $\begin{array}{r}19 \\
14 \\
8 \\
6 \\
5 \\
6 \\
5 \\
4\end{array}$ & $\begin{array}{c}3 \\
3 \\
1.5 \text { to } 2 \\
3 \\
1 \\
2 \\
2 \\
1\end{array}$ & $\begin{array}{c}2 \text { to } 3 \\
2 \text { to } 2.5 \\
2.5 \\
3 \\
2 \\
2 \\
2 \\
1.5\end{array}$ \\
\hline
\end{tabular}

necessary to maintain a normal BMR did not change significantly in any of these patients over periods ranging from four to nineteen years.

\section{COMPARISON OF THE EFFECTS OF ORAL THYROID AND INTRAVENOUS THYROXINE}

Data bearing on this point are available in two cases. In one case, $0.2 \mathrm{mgm}$. of thyroxine daily for three months restored the BMR to -14 per cent, a level which could subsequently be maintained with one grain of dried thyroid daily. In the other case, $0.6 \mathrm{mgm}$. of thyroxine daily for six weeks restored the BMR to +1 per cent, a level which at that time could be maintained with a daily dose of three grains of oral dried thyroid daily.

\section{DISCUSSION}

The myxedematous subject certainly does not react to thyroid medication with the mathematical predictability of a machine. Some individuals require a larger dose than others, both absolutely and in proportion to their body weight. Factors other than thyroid medication obviously affect the BMR, since this may vary from time to time without change in the dose of thyroid. Nevertheless, beyond rather narrow limits the myxedematous patient appears to be at the mercy of his thyroid medication. If this is lowered below a certain point, he will always develop evidences of deficiency; if it is raised above a certain point, he will develop signs of toxicity. The intermediate range of dosage is not great, the leeway being not more than a grain or so daily. $\mathrm{He}$ apparently never develops a tolerance to dried thyroid, and never requires more than about three grains a day for full maintenance.

\section{CONCLUSIONS}

(1) Myxedematous patients do not develop any tolerance to dried thyroid, even after years of medication.

(2) In myxedema, the dose of dried thyroid necessary to restore the basal metabolic rate to normal regularly lies between one and three grains daily. It may, however, vary somewhat in the same individual from time to time.

(3) The relationship between BMR and the dose of dried thyroid tends to be linear, at least while the BMR is subnormal.

(4) The quantitative response of the myxedematous subject to dried thyroid is specific and reproducible. The diagnosis of myxedema may properly be questioned if this characteristic response cannot be demonstrated.

\section{BIBLIOGRAPHY}

1. Means, J. H., The Thyroid and Its Diseases. J. B. Lippincott Co., Philadelphia, 1937.

2. Means, J. H., and Lerman, J., The symptomatology of myxedema: its relation to metabolic levels, time intervals and rations of thyroid. Arch. Int. Med., 1935, 55, 1.

3. Thompson, W. O., and Thompson, P. K., Low basal metabolism following thyrotoxicosis. I. Temporary type without myxedema, with special reference to the role of iodine therapy. J. Clin. Invest., 1928, 5, 441.

4. Winkler, A. W., Hypometabolism following subtotal thyroidectomy. Internat. Clin., 1941, 1, 255. 